\title{
Physical activity and other health- related behaviors in adults from Oradea, Romania. Facts and social factors
}

Authors' Contribution: A Study Design

B Data Collection

C Statistical Analysis

D Data Interpretation

E Manuscript Preparation

F Literature Search

G Funds Collection

\author{
Raluca BuhașABCDEF, Sorana Săveanu ${ }^{A B C D E F}$, Claudia Bacter ${ }^{A B C D E F}$ \\ Faculty of Social Sciences, University of Oradea, Romania
}

\section{abstract}

Background: Findings indicate a direct relation between engagement in physical activities, dietary habits and a healthy lifestyle. An active life and a nutritional diet are associated with substantial health benefits. But people's interest in health outcomes as well as their level of engagement in physical activities is influenced by a wide array of determinants, among which socio-cultural factors play an important role.

Material and methods: Our paper investigates how much Romanian adults are engaged in exercising and aims to identify their health-related behaviors Data were collected by questionnaire from 400 subjects.

Results: Research results indicate that not many Romanian adults are interested in their health. However, those who are preoccupied with this tend to adopt a healthy lifestyle by engaging themselves in various physical activities, feeling motivated about this and eating correctly, as well.

Conclusions: The level of engagement in physical activity is individually determined by social covariates, such as education, income, occupational status or age.

Key words: physical activity, social factors, sport involvement, health-related behaviors, adults.

\section{article details}

Article statistics: Word count: 3,314; Tables: 0; Figures: 9; References: 30

Received: June 2020; Accepted: August 2020; Published: November 2020

Full-text PDF: http://www.balticsportscience.com

Copyright @ Gdansk University of Physical Education and Sport, Poland

Indexation: Celdes, Clarivate Analytics Emerging Sources Citation Index (ESCI), CNKI Scholar (China National Knowledge Infrastructure), CNPIEC, De Gruyter - IBR (International Bibliography of Reviews of Scholarly Literature in the Humanities and Social Sciences), De Gruyter - IBZ (International Bibliography of Periodical Literature in the Humanities and Social Sciences), DOAJ, EBSCO - Central \& Eastern European Academic Source, EBSCO - SPORTDiscus, EBSCO Discovery Service, Google Scholar, Index Copernicus, J-Gate, Naviga (Softweco, Primo Central (ExLibris), ProQuest - Family Health, ProQuest - Health \& Medical Complete, ProQuest - Illustrata: Health Sciences, ProQuest - Nursing \& Allied Health Source, Summon (Serials Solutions/ProQuest, TDOne (TDNet), Ulrich's Periodicals Directory/ulrichsweb, WorldCat (OCLC)

Funding: This research received no specific grant from any funding agency in the public, commercial, or not-for-profit sectors.

Conflict of interests: Corresponding author:

Open Access License:
Authors have declared that no competing interest exists.

Dr Raluca Buhas, Universitatii street, no.1, postal code 410087, Oradea, Romania; phone: +40 773 797515; e-mail: ralubuhas@gmail.com

This is an open access article distributed under the terms of the Creative Commons Attribution-Non-Commercial-NoDerivatives 4.0 International (https://creativecommons.org/licenses/by-nc-nd/4.0/), which permits use, distribution and reproduction in any medium, provided the original work is properly cited, the use is non-commercial and is otherwise in compliance with the license. 


\section{INTRODUCTION}

Over the years, the definition of physical activity has been standardized and it is now accepted among professionals: physical activity represents any bodily movement produced by muscles that expands energy beyond resting levels [1, 2, 3]. A wider approach to physical activity tackles its type, duration, frequency and intensity, as well as the social setting in which physical activities occur $[4,5]$. However, engagement in physical activity is seen as a healthy behavior. Without any doubt, an adequate level of physical activity provides substantial health benefits at individual level [6, 7]. On the other hand, a sedentary lifestyle acts in the opposite direction. It is demonstrated that regular physical activity provides numerous health benefits and prevents a variety of chronic diseases, such as diabetes, cardiovascular disease, cancer, or obesity, while the most physically active people present the lowest risk in this regard $[2,8]$.

Overall, a regular physical activity contributes to an increased wellbeing and quality of life. In this regard, organizations and institutions all over the world are concerned about the influence of an inactive lifestyle on public health, as well as on health budgets and economy [9]. The European Commission's White Paper "A Strategy for Europe on Nutrition, Overweight and Obesity related health issues" [10], the White Paper on Sport [11], the World Health Organization Global Strategy on Diet, Physical Activity and Health [12] approach this matter and promote physical activity and a balanced diet. Based on these regulations, Member States are urged to adopt and promote national policies and strategies to encourage an active and healthy lifestyle. The role of the Governments is crucial in this regard, but civil society, nongovernmental organizations and the private sector can be significant players in influencing individual health-related behaviors. A sustainable strategy at an international and national level is the key element in reducing health-related risks and improving public health.

Following these international regulations, Romania also elaborated a national strategy on physical activity and performance sport. The strategy outlines a need to promote an active and healthy lifestyle among all social and economic groups [13] taking into consideration that $63 \%$ of Romanian citizens are not involved in any physical activity or do not play sports [14].

In the light of the abovementioned aspects, our paper aims to investigate the level of engagement in physical activities and other healthy practices among adults in Romania. In this regard, our study identifies main social covariates of sport involvement and health-related behaviors by approaching dietary habits, attitudes toward sport and self-perceived weight.

\section{ENGAGEMENT IN SPORT AND PHYSICAL ACTIVITIES}

The Special Eurobarometer on sports [14] shows that almost half of European citizens never exercise or play sport and the tendency to engage in any type of physical activity has decreased over the last years. Only $7 \%$ of Europeans practice sport on a regularly basis (minimum five times/week) and the proportion of people who exercise the most is registered mainly in Northern countries (such as Finland, Sweden or Denmark). On the other hand, Eastern and Southern European countries (among which, Romania) have the lowest levels of people engaged in exercising or playing sports.

In terms of duration, frequency and intensity, experts have recommended frequencies of at least 3 days/week and a minimum of 150 minutes/week of moderate to vigorous activity. A moderate intensity physical activity of 150-300 minutes/week provides substantial health benefits [2]. According to the recommendations of the World Health Organization [12], adults should engage in at least 30 minutes of regular moderate physical activity per day in order to reduce the risk of developing chronic diseases. However, only about half of Europeans engage in a moderate level of physical activity during a week, spending one 
hour or less per day doing so, while $15 \%$ of them do not walk for 10 minutes at a time at all during a week [14]. A more vigorous physical activity is supposed to induce more health benefits. Even if for sedentary people low levels of physical activity are better than none, there is still a debate among experts regarding the optimal and the minimal volume of exercise for health benefits [8]. Types of physical activity also have different health outcomes. While, for example, aerobic activities (such as swimming) are more associated with the cardio-vascular system, weight-lifting or balance-training activities improve muscle strength, endurance or posture [2].

As mentioned before, physical activity is seen in terms of its volume, including type, frequency, intensity and duration. However, a more complex approach also includes motives for engaging in physical activities and individual attitudes toward it [15]. People act differently, and the self-determination theory (SDT) analyzes, among other theories, how intrinsic and extrinsic motivation determine individual differences. Social and cultural factors facilitate or lower people's initiative, motivation, engagement and persistence in various activities, including in physical activity [16]. Among the most important reasons for Europeans to engage in sport or physical activity is to improve the health status or fitness, to relax, to have fun or to increase performance. On the other hand, inactive people have their reasons for not engaging in such activities. By far, the main reason in this regard is lack of time, but there are also other reasons, such as lack of motivation or interest in sport, or lack of sport facilities $[14,17,18]$.

\section{Health-RELATEd Behaviors}

Unquestionably, a healthy lifestyle is determined by many factors, among which exercise and diet are the key elements. The percentage of overweight and obese people in the EU population has increased very much over the past decades, generated by poor diet and inactive lifestyle [10]. In this context, the World Health Organization [12] recommends a balanced diet in order for people to remain healthy even in their seventh, eighth or ninth decade of life. People are urged to adopt a diet that can ensure a healthy weight and energy by limiting the intake of free sugars, salt and fats and increasing the consumption of vegetables, fruits, grains, nuts. European regulations tackle the role of social and cultural environment, including the media, in shaping healthy eating habits [10]. A large body of research pointed out the need to have a diet rich in fiber foods (fruits, whole grains and vegetables) in order to reduce the risk of degenerative diseases [19, 20]. According to the World Health Organization [21], an adult should eat at least 25 grams of fiber daily. If in some European countries this value is respected, an average Romanian adult eats only 9-10 grams of fibers per day, so much lower than needed. Moreover, very few Romanians consume whole grain foods [20].

A normal body weight and a good health status are based on adequate nutrition and engagement in physical activity. The lack of one of these two elements may cause health imbalance. Literature review outlined the most important determinants of healthy aging. People who live longer are nonsmokers, consume alcohol in moderation, engage regularly in physical activities, and their body mass index (BMI) is in the normal range [22]. Research results indicate an association between higher levels of physical activity and lower BMI, while people with BMI above normal (overweight or obese people) tend to be rather sedentary [15]. Of course, an inactive life is associated with an increase in BMI [23, 24, 25].

\section{WHO DOES GET INVOLVED IN SPORT ACTIVITIES?}

A large body of research outlined the relation between various social-environmental and individual related determinants of physical activity and sport involvement $[2,8,26]$. In general, physical activity involvement and health benefits are strongly associated with socio-cultural factors like age, gender, education, income [4, 27-29]. 
Overall, at the level of EU countries men tend to be more engaged in physical activities than women, and this difference is noticed especially in the 15-24 age group [14]. A similar gender difference was found in other studies with female subjects showing a lower level of their engagement in physical activities $[4,15]$. In terms of age, as people get older, the level of regular physical activity also decreases [14].

Likewise, the level of education and individuals' or family economic status influence physical activity involvement. People with lower levels of education and income are not as engaged in physical activities as other social groups [4,14]. Moreover, even people with intermediate income or education tend to be less healthy and active than others [15, 28, 30].

\section{MATERIAL AND METHODS}

Research methodology. Data presented in this paper is based on research conducted in Oradea (a city in the North-Western part of Romania) between May and July 2019. Data were collected by a questionnaire. The examined population consisted of adults (18 years old and over) from Oradea. Subjects were selected using a non-random sampling procedure. The selection was based on proportional quotas using age, education, gender, neighborhood and type of residence as the selection criteria.

Research objectives. Overall, our study aims to investigate the level of engagement in physical activity and sport as well as other health-related practices, and also to identify social covariates of sport involvement. Starting from this point, we delineated the following research objectives: O1) a descriptive analysis of the level of engagement in physical activity; O2) identification of sport involvement and other health-related behaviors; O3) analysis of social covariates of engagement in physical activity. Furthermore, data were analyzed, and results were discussed according to these research objectives.

Sample description. The final data set contained 400 cases. The structure by gender indicates 206 female subjects (51.5\%) and 194 male subjects (48.5\%). The average age is 46.8 (with 15.4 standard deviation). In terms of the level of education, $45 \%$ of the subjects have a high school diploma, 35\% graduated from higher education $(27.3 \%$ have a Bachelor's diploma and 7.8\% hold a Master's degree diploma or higher). Among the examined subjects, $15.5 \%$ graduated from vocational school or do not obtained a high school diploma, while other $4.5 \%$ have less than 8 graduated classes.

Regarding the marital status, $61.2 \%$ of the subjects have partners (58.9\% are married and $2.3 \%$ are engaged in civil partnerships), $20.1 \%$ are single, while $18.8 \%$ are divorced, separated or widowed. Most respondents currently work: $54.1 \%$ are employed and $14 \%$ are self-employed, but a rather high percentage of them (31.8\%) do not have a job at the moment.

\section{RESULTS AND DISCUSSION}

\section{ENGAGEMENT IN SPORT AND ATTITUDES TOWARD PHYSICAL ACTIVITY}

First, we aimed to identify how our subjects relate to physical activity and sport. In this regard, we wanted to investigate their level of engagement in various physical activities and their attitudes toward sport as well as motivations to adopt an active and healthy lifestyle.

More than half of the subjects (62.8\%) declare that they are engaged in some type of physical activity. However, when we analyzed the volume of their physical activity, the data are not too optimistic: only $34.9 \%$ of them are involved in regular activity. In terms 
of frequency, they declare exercising daily or at least several times per week. $27.9 \%$ of them are involved in physical activity less frequently, several times during a month. There is a considerable percentage of people who declare that they do not play any sports at all (37.2\%) (Figure 1). Our results comply in this regard with other findings among Romanian adult population that point out the high percentage of people having a sedentary lifestyle [14].

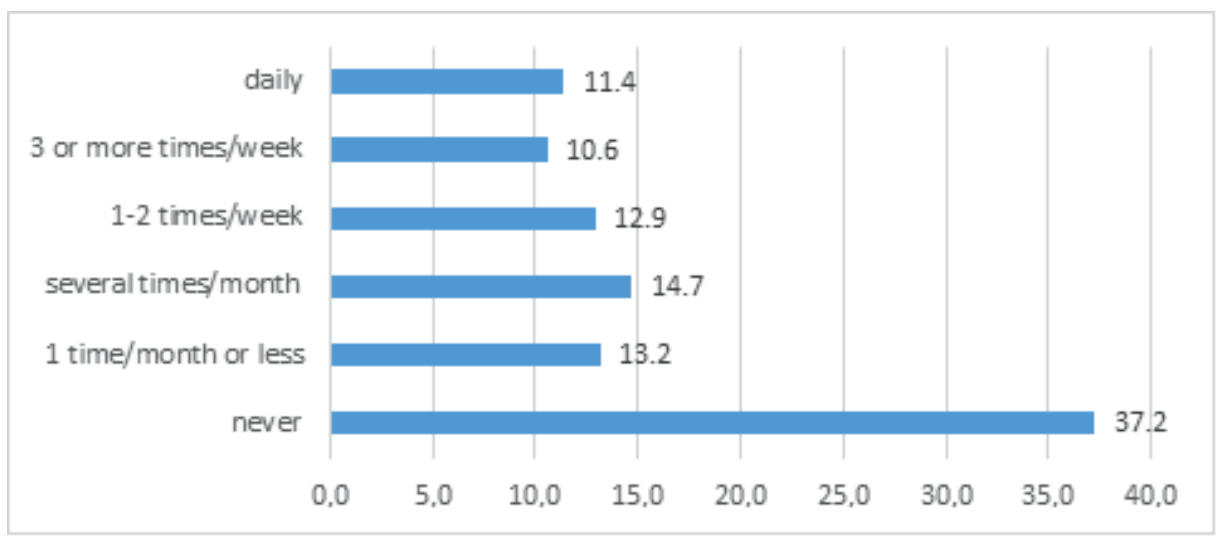

Fig. 1. Frequency of physical activity in the last 3 months (\%)

For a more in-depth analysis, in our further analyses we used a dichotomic variable referring to $62.8 \%$ of subjects who exercise and $37.2 \%$ who are not engaged in any physical activity. Regarding the intensity of physical activity, a great percentage of the respondents (71\%) declare that they walk approximately 30 minutes daily, while $11.5 \%$ of them use a bicycle at least once every two days. So, active subjects prefer to be engaged more in aerobic activities.

As outlined in the literature review, engagement in physical activity is determined by intrinsic and extrinsic motivation $[15,16]$. The main reason for which the investigated subjects are involved in sports activities is the one regarding their health status. Our results are in line with other findings: $93.2 \%$ of the investigated subjects declare that exercising is important to them because they want to be healthy and fit. The second reason refers to the impact that physical activity has on their mental state: sport reduces stress and induces a general good state of mind. Regarding this aspect, $57 \%$ of the subjects say that sport makes them happy. From another perspective, involvement in competitive activity seems not to be one of the reasons why people play sports (Figure 2).

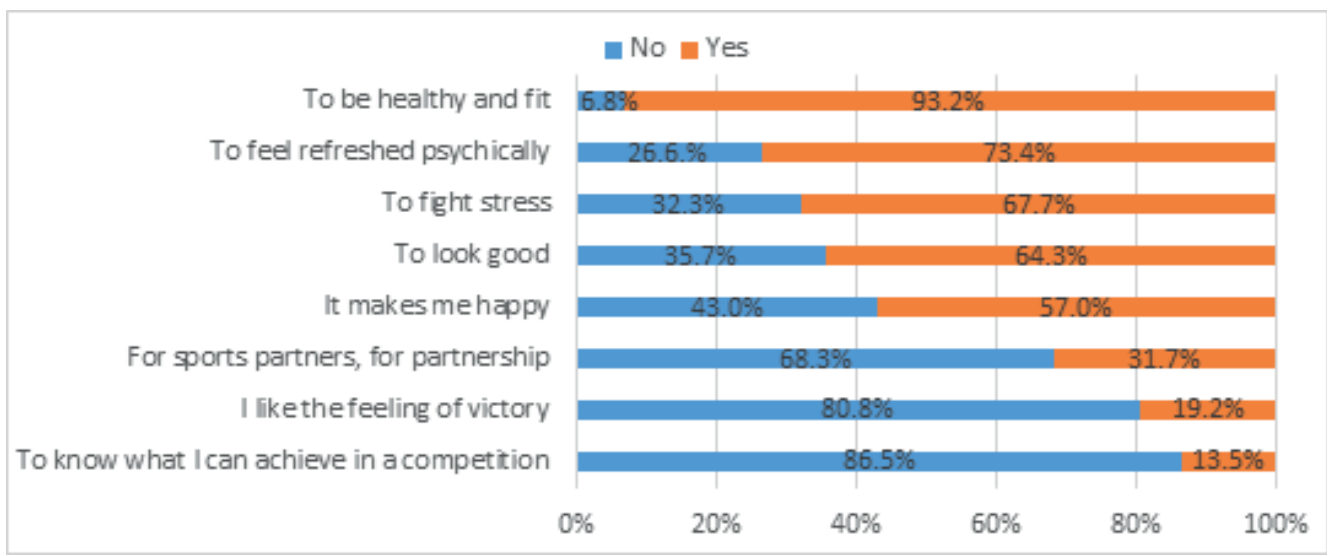

Fig. 2. Motivation for playing sports 
In the case of those subjects who are not engaged in physical activity, or not as much as they would want to, the main reason for being inactive refers to time management, as also other studies showed. Most of the subjects declare that they do not have the necessary time to exercise, or they declare that they are too comfortable to get involved in this kind of activity. Lower percentages are recorded for reasons that refer to the lack of opportunities to practice the desired sport (Figure 3).

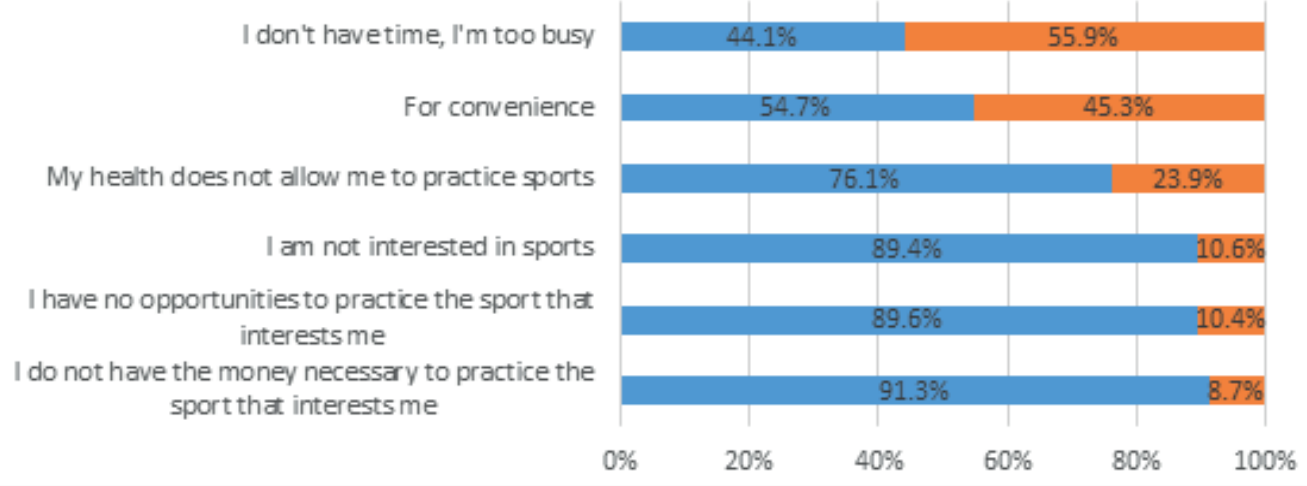

Fig. 3. Motivations for not playing sports

\section{SPORT INVOLVEMENT AND OTHER HEALTH-RELATED BEHAVIORS}

Data show that the majority of the investigated subjects are interested in their health state. $80.4 \%$ of them declare that they are preoccupied with their health to a very great extent or a great extent. Analyses indicate a significant relationship regarding the interests in their health and involvement in sport (chi-square 16.16, $p=0.001$, df 3). Data suggests that subjects who do not exercise at all are less interested in their health than others (Figure 4). These results indicate that active people are involved in physical activity and tend to adopt a healthy lifestyle because they aim to have many health outcomes.

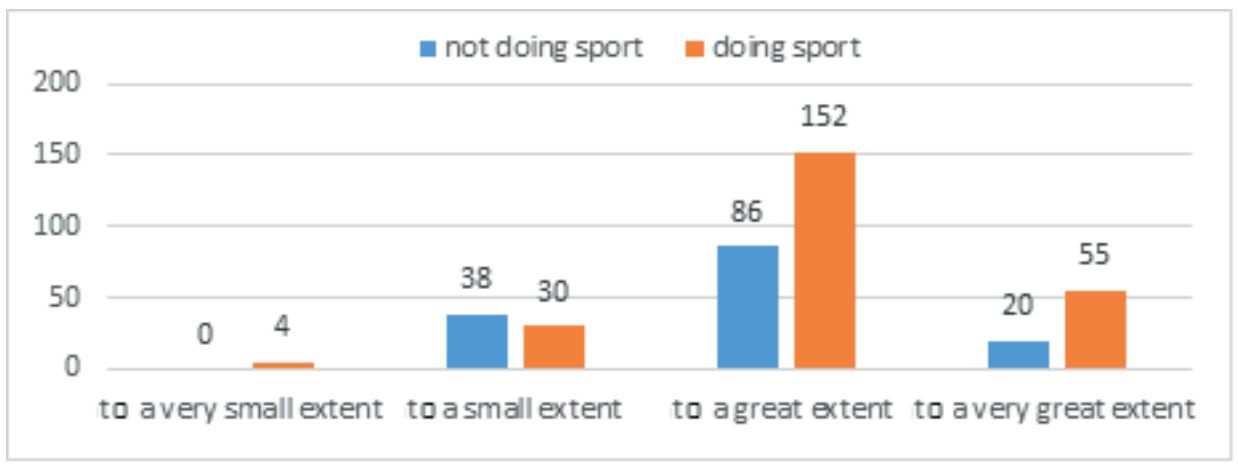

Fig. 4. Subjects' concern about their own health status (number of cases)

We were also interested in identifying dietary habits among our subjects. We investigated water consumption and eating habits in this regard. On average, the subjects involved in our research drink $2 \mathrm{~L}$ of water/day (with 0.8 standard deviation). There is a very small difference regarding the amount of water drunk (2.08L/day) by subjects who practice sport as compared to those who are not engaged at all in any physical activity (1.92L/day). The difference between those values is not statistically significant. 
Regarding their eating behavior, $22.4 \%$ of the subjects declare that they eat bread at each meal. $37 \%$ of them often eat bread at each meal, $31.5 \%$ rarely do this and only $9 \%$ never eat bread at each meal. These results are prone to generate some debate. Taking into consideration the WHO recommendation that, in order to have a healthy lifestyle and prevent certain diseases, the diet should contain much fiber food, e.g. whole grains. The quality of the bread Romanians eat and its nutritional properties remain to be investigated in future research. Moreover, our analyses show a significant relationship regarding this eating behavior and subjects' engagement in physical activity (chi-square 28.2, $p=0.000$, df 3 ). The number of respondents who do not exercise at all and always eat bread at each main meal is greater compared to those who have an active life. By contrast, more active subjects state that they never eat bread at each main meal compared to those who are sedentary (Figure 5).

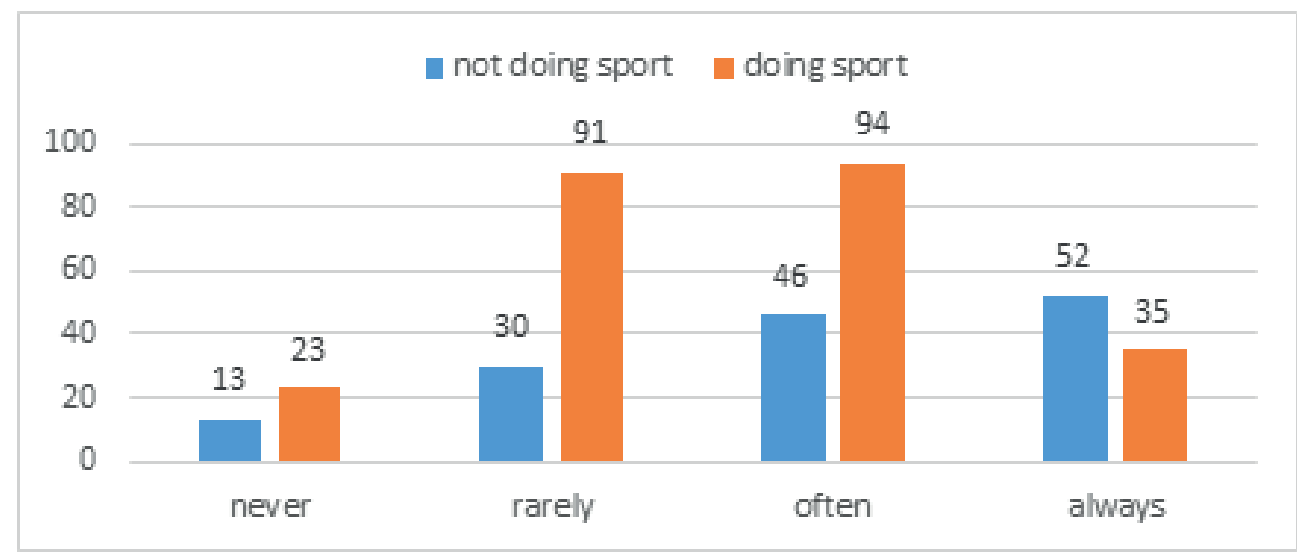

Fig. 5. Frequency of eating bread at every main meal (number of cases)

Also, in our study we registered the self-perceived body weight and also the real body weight (using Body mass index - BMI) based on data received from subjects regarding their height and weight. Regarding the engagement in physical activity, analyses do not show a significant relationship when taking into consideration the self-perceived body weight, but we identified a significant relationship for the BMI (chi-square 17.8, p=0.001, df 4). A significant relationship is registered in the case of subjects with normal body weight. Among them, there is a significantly higher proportion of persons who are involved in sport activities (adjusted residual 3.0). Also, a significant difference was registered in the case of subjects with grade II obesity: few of them are physically active (adjusted residual 3.2) (Figure 6).

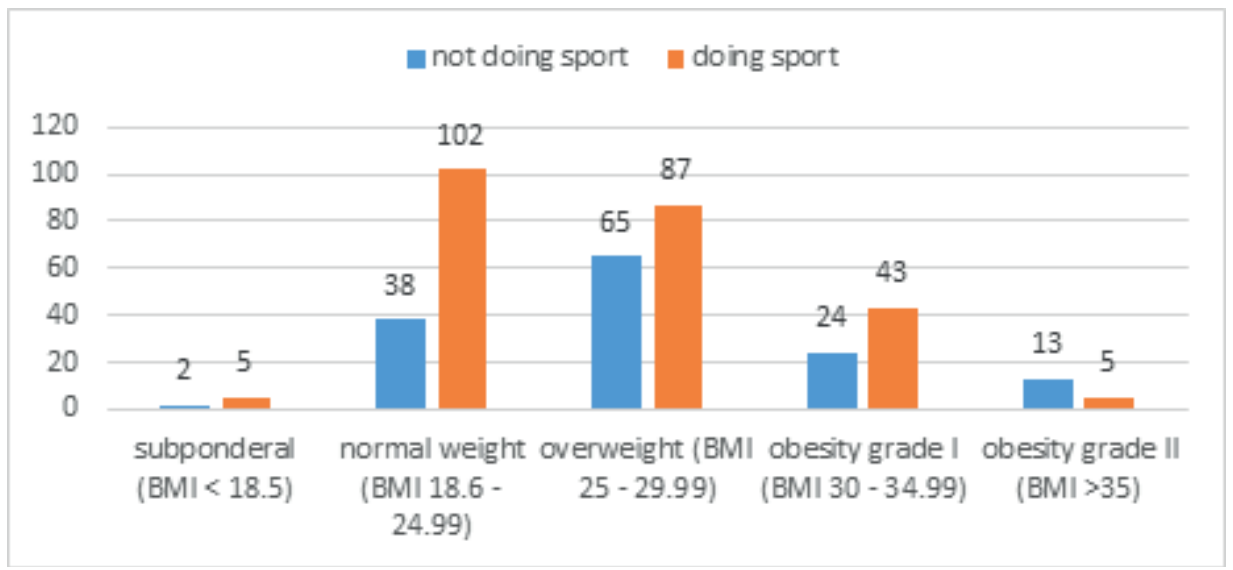

Fig. 6. Relationship between the BMI and exercising (number of cases) 
Among subjects who consider themselves to have a weight over the normal level, $63.1 \%$ declare that they take measures to lower their weight. Weight management regards both main pillars of a healthy lifestyle: the first measure that is mentioned by subjects refers to changing eating behaviors (85.9\% of the respondents declare they reduce the amount of food intake) and the second one refers to physical activity ( $49.6 \%$ declare that they exercise).

\section{SOCIAL COVARIATES OF SPORT INVOLVEMENT}

The analysis did not indicate significant differences regarding gender. This result is contrary to other findings that differentiated between women's levels of physical activity and those of men. But age seems to be one of the covariates for involvement in physical activity among our respondents $(\mathrm{t}=5.4, \mathrm{p}=0.000)$. The average age of inactive subjects is higher (52 years) than the age of those who exercise (43.4 years). As people get older, they are less willing to get involved in physical activity.

The level of education also presents significant differences (chi-square $=35.7, p=0.000$, df 4). Data suggests that subjects that did not graduate from high school (do not have a high school diploma) are less involved in sport activities (adjusted residual 5.0). As regards those who have a higher-education diploma, more of them exercise (adjusted residual 4.3). Results indicate that physical activity is associated with a higher level of education, complying also with other studies (Figure 7).

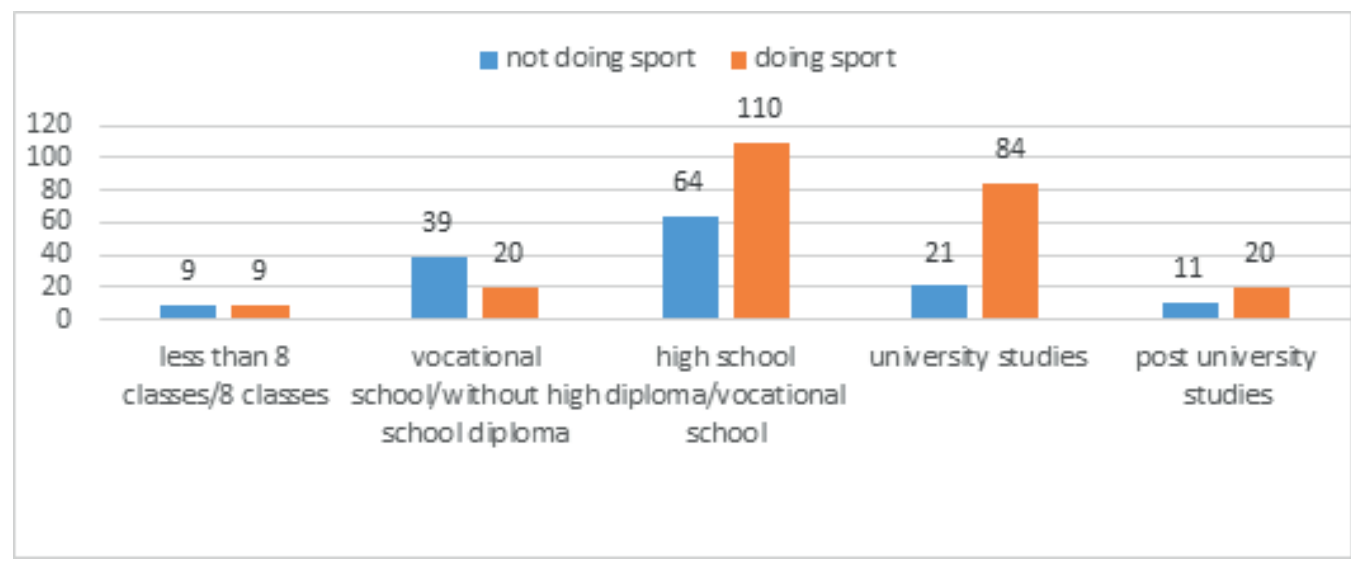

Fig. 7. Level of education (number of cases)

We identified a significant relationship in the case of subjects' occupational status (chi-square $=31.8, \mathrm{p}=0.000, \mathrm{df} 2$ ). Respondents who currently do not have a paid job are less involved in physical activity, as compared to those who work (Figure 8).

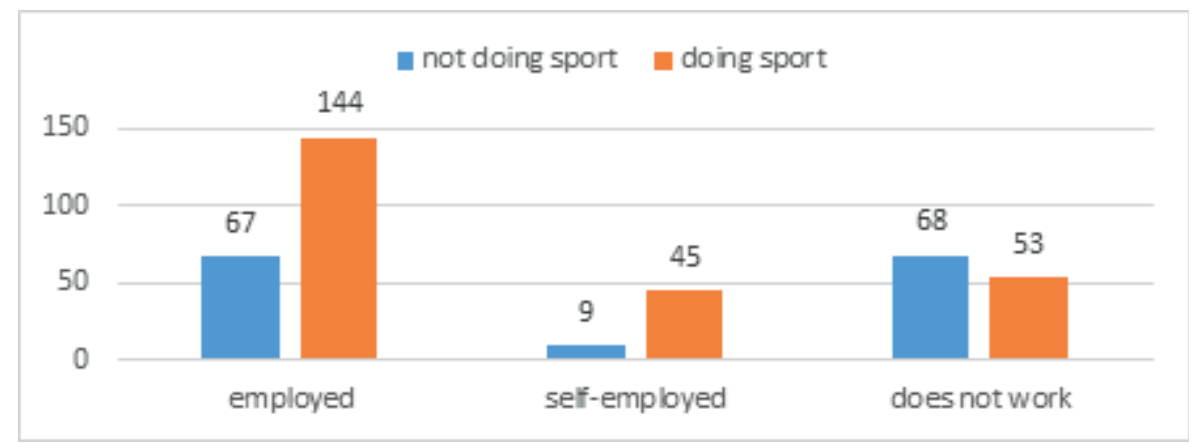

Fig. 8. Occupational status (number of cases) 
The level of income also explains differences between subjects who are engaged in physical activity and those who are not (chi-square $=32.4, p=0.000$, df 5). A higher level of income implies better orientation toward sport (Figure 9).

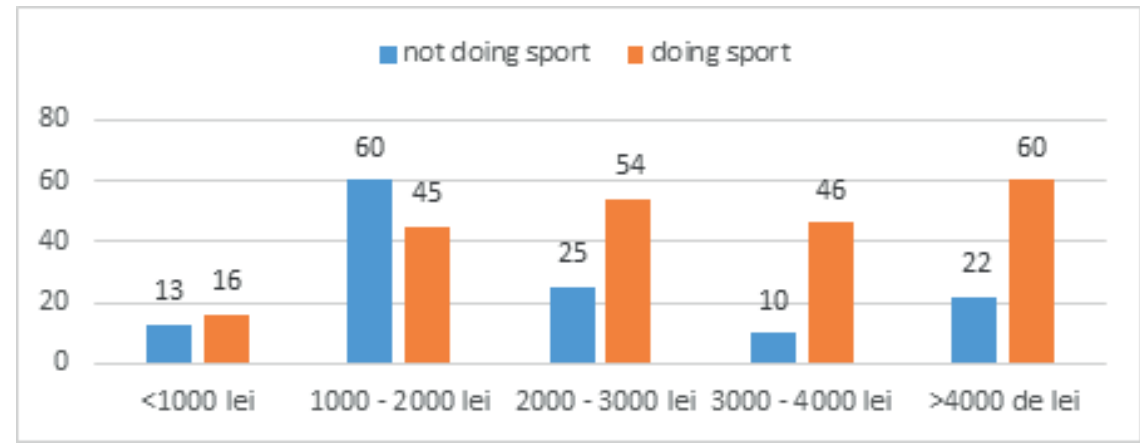

Fig. 9. Income level (number of cases)

\section{CONCLUSIONS}

Overall, our research results are in line with other findings. The proportion of people who are engaged in a regular and moderate physical activity is not as high. A considerable percentage of people declare that they do not play any sports at all.

People who are interested in ensuring themselves good health are also engaged in physical activity and find their motivation to do that. They also pay attention to their dietary habits, trying to adopt a balanced nutrition, with enough amount of water intake and less bread. A healthy lifestyle is not only related to physical body, but also to mental state. People feel that sport helps them overcome stress and creates a good state of mind. However, less active people will always find reasons for not getting involved in physical activity, regardless if we take into consideration time, lack of motivation or opportunities. Moreover, there is a significant relationship between the BMI and an active life: people with a normal $\mathrm{BMI}$ are more prone to exercise, while obese individuals are rather sedentary.

Social factors are important determinants for the level of engagement in physical activity. Overall, people having a high socio-economic status tend to exercise more than people with poor levels of education or income. Getting involved in a regular physical activity implies time, financial resources and an adequate attitude toward sport. But, as people get older, their level of physical activity decreases.

Future research could thoroughly analyze the relationship between engagement in physical activity and dietary habits or other social covariates. Still, our research results point out that Romanian adults are not as active or preoccupied about their health state as they should be.

\section{REFERENCES}

[1] Bouchard C, Blair SN, Haskell WL. Physical activity and health. Champaign, IL: Human Kinetics; 2007.

[2] Powell K, Paluch A, Blair S. Physical Activity for Health: What Kind? How Much? How Intense? On Top of What? Ann Rev Public Health. 2011;32(1):349-365. https://doi.org/10.1146/annurev-publhealth-031210-101151

[3] O'Brien W, Issartel J, Belton S. Evidence for the Efficacy of the Youth-Physical Activity towards Health (Y-PATH) Intervention. Adv Phys Educ. 2013;3(4):145-153. https://doi.org/10.4236/ape.2013.34024

[4] Gauvin L. Social Disparities and Involvement in Physical Activity: Shaping the Policy Agenda in Healthy Living to Successfully Influence Population Health. Quebec, Canada: University of Montreal; 2003.

[5] Buhaș S, Herman G, Ștef M. Aspects Regarding Speed Development in Football Game in 12-14 Years Old Children. GeoSport for Society. 2018;8(1):21-30.

[6] Ilieș DC, Buhaș R, Ilieș M, Ilieș A, Gaceu O, Pop AC, Marcu F, Buhaș SD, Gozner M, Baias S. Sport Activities and Leisure in Nature 2000 Protected Area-Red Valley, Romania. J Environ Protect Ecology. 2018a;19(1):367-372. 
[7] Vujko A, Plavsa J. Opportunities for development of paintball as part of sports recreational and anti-stress tourism in Fruška Gora Mountain (Serbia). Geo. Journal of Tourism and Geosites. 2011;4:95-106. [Available at http://gtg. webhost.uoradea.ro/PDF/GTG-1-2011/9_79_Vujko.pdf] [Accessed on 3 April, 2020].

[8] Warburton D, Nicol C, Bredin S. Health benefits of physical activity: the evidence. Can Med Assoc J. 2006;174(6):801809. https://doi.org/10.1503/cmaj.051351

[9] Marcu V, Buhas S. Sports Organizations - Management and Science. Procedia - Social and Behavioral Sciences. 2014;117:678-682. https://doi.org/10.1016/j.sbspro.2014.02.281

[10] Commission of the European Communities. A Strategy for Europe on Nutrition, Overweight and Obesity related health issues (white paper). Brussels: COM 279 final; 2007a. [Available at https://eur-lex.europa.eu/LexUriServ/ LexUriServ.do?uri=OJ:C:2010:008E:0097:0105:EN:PDF] [Accessed on 21 April, 2020].

[11] Commission of the European Communities. White Paper on Sport (white paper). Brussels: COM 391 final; 2007b. [Available at https://eur-lex.europa.eu/legal-content/EN/TXT/?uri=CELEX\%3A52007DC0391] [Accessed on 21 April, 2020].

[12] World Health Assembly Resolution WHA57.17. Global strategy on diet, physical activity and health. World Health Organization, Geneva: May 22, 2004. [Available at https://apps.who.int/gb/ebwha/pdf files/WHA57/A57 R17-en.pdf] [Accessed on 21 April, 2020].

[13] Ministry of Youth and Sports (Romania). Strategia nationala pentru sport 2016-2032 [The National Strategy for Sport 2016-2032]. Bucharest, Romania; 2016. Romanian. [Available at http://mts.ro/wp-content/uploads/2016/02/ Strategia-nationala-pentru-SPORT-v2016-v2.pdf] [Accessed on 4 May, 2020].

[14] Sport and physical activity (Special Eurobarometer 472). Brussels: European Commission; 2018. [Available at https:// data.europa.eu/euodp/en/data/dataset/S2164_88_4_472_ENG] [Accessed on 22 April, 2020].

[15] Hirvensalo M, Lintunen T. Life-course perspective for physical activity and sports participation. Eur Rev Aging Phys Act. $2011 ; 8: 13-22$. https://doi.org/10.1007/s11556-010-0076-3

[16] Deci EL, Ryan RM. Self-determination theory and the facilitation of intrinsic motivation, social development, and well-being. Am Psychol. 2000;55:68-78. https://doi.org/10.1037/0003-066X.55.1.68

[17] Onet A, Ilies DC, Buhas S, et al. Microbial Air Contamination in Indoor Environment of University Sports Hall. J Environ Protect Ecology. 2018;19(2):694-703.

[18] Ilies DC, Buhas R, Ilies A, et al. Indoor Air Quality Issues. Case Study: The Multipurpose Sports Hall of the University of Oradea. Environ Eng Management J. 2018b;17(12):2999-3005. https://doi.org/10.30638/eemj.2018.300

[19] Dias JS. Nutritional Quality and Health Benefits of Vegetables: A Review. Food Nutrition Sci. 2012;3:1354-1374. https://doi.org/10.4236/fns.2012.310179

[20] Tarcea M, Fazakas Z, Szucs V, et al. Mean Dietary Fiber Intake of Romanian Adults Results of a Survey Questionnaire. Revista de Chimie, 2017;68(9):2083-2087. https://doi.org/10.37358/RC.17.9.5828

[21] World Health Organization. Diet, Nutrition, and the Prevention of Chronic Diseases Report of a Joint WHO/FAO Expert Consultation. Geneva: World Health Organization; 2003. [Available at https://apps.who.int/iris/bitstream/ handle/10665/42665/WHO TRS 916.pdf;jsessionid=FF4730C69B6E96036B08C51705B697C7?sequence=1] [Accessed on 22 April, 2020].

[22] Peel N, McClure R, Bartlett H. Behavioral Determinants of Healthy Aging. Am J Prevent Med. 2005;28(3):298-304. https://doi.org/10.1016/j.amepre.2004.12.002

[23] Hill JO, Wyatt HR. Role of physical activity in preventing and treating obesity. J Appl Physiol. 2005;99:765-70. https:// doi.org/10.1152/japplphysiol.00137.2005

[24] Hu FB, Li TY, Colditz GA, Willett WC, Manson JE. Television watching and other sedentary behaviors in relation to risk of obesity and type 2 diabetes mellitus in women. JAMA. 2003;289:1785-91. https://doi.org/10.1001/jama.289.14.1785

[25] Vandelanotte C, Sugiyama T, Gardiner P, Owen N. Associations of leisure-time internet and computer use with overweight and obesity, physical activity and sedentary behaviors: cross-sectional study. J Med Internet Res 2009;11:e28. https://doi.org/10.2196/jmir.1084

[26] Dragos P, Lucaciu G, Trifa I, Stef M., Szabo-Alexi P, Buhas S. Aspects Regarding the Influence of Communication on the Motivation of Employees in Some Sports Organizations. Proceedings of the 4th International Conference of the Universitaria Consortium (ICU 2018): The Impact of Sport and Physical Education Science on Today's Society. 2018a:73-77.

[27] Braveman P, Gottlieb L. The Social Determinants of Health: It's Time to Consider the Causes of the Causes. Public Health Reports, Supplement 2. 2014;129:19-31. https://doi.org/10.1177/00333549141291S206

[28] Braveman P, Egerter S, Williams D. The Social Determinants of Health: Coming of Age. Ann Rev Public Health. 2011;32:381-398. https://doi.org/10.1146/annurev-publhealth-031210-101218

[29] Dragos P, Lucaciu G, Dinis I, Stef M, Szabo-Alexi P, Buhas S. Concepts Concerning the Content of Children's Training in Some Sport Games. Proceedings of the 4th International Conference of the Universitaria Consortium (ICU 2018): The Impact of Sport and Physical Education Science on Today's Society. 2018b:67-72.

[30] Braveman PA, Cubbin C, Egerter S, Williams DR, Pamuk E. Socioeconomic disparities in health in the United States: What the patterns tell us. Am J Public Health. 2010;14:20-35. https://doi.org/10.2105/AJPH.2009.166082 